\title{
Lomitapide Mesylate
}

National Cancer Institute

\section{Source}

National Cancer Institute. Lomitapide Mesylate. NCI Thesaurus. Code C83892.

A methanesulfonic acid form of lomitapide, a small molecule inhibitor of microsomal triglyceride transfer protein. 